\title{
ANALOGIA E INTERPRETAÇÃO EXTENSIVA: apontamentos desses institutos no Direito Tributário brasileiro
}

ANALOGY AND EXTENSIVE INTERPRETATION: notes about those institutes in brazilian Tax Law

Florence Haret

\begin{abstract}
Resumo:
Sabe-se bem que a ordem brasileira institui um ordenamento completo e, para realizar tal inteireza e auto-suficiência, recorre a mecanismos como a analogia e a interpretação extensiva. Das duas categorias ora estudadas, verificamos que, por diferentes métodos, elas buscam criar sentido de unidade, dar coesão, atribuir fechamento ao direito positivo de forma a afirmar que todos, e absolutamente todos os casos encontram solução dentro da ordem posta. Deste modo, sob a imposição de que ao juiz cabe julgar todas as controvérsias que se apresentam ao seu exame mediante norma pertencente ao sistema, a ordem jurídico-brasileira prescreve duas normas de sobrenível: as regras gerais inclusiva, aplicáveis ao tipo na forma-de-construção, e as exclusivas, assumidas no tipo na forma tabular. $\mathrm{Na}$ primeira, a própria noção de classe admite, inclusão; na segunda, a taxatividade é condição auto-exclusivista, acolhendo somente aqueles específicos preceitos que lá se encontram discriminados individualmente.Assim sendo, tanto a extensão analógica (analogia) quanto a interpretação extensiva buscam seus fundamentos nessas normas superiores - normas gerais inclusivas e/ou exclusivas - que lhe dão competência para, mediante argumentum a simili ou a contrario, respectivamente, construir a norma que dá resposta jurídica ao caso em concreto. Neste mesmo sentido, os modos de identificação do tipo - forma-de-construção ou tabular estão diretamente relacionados às maneiras interpretativas de aplicação do direito: analógicas ou extensivas. Está nesta análise a resposta para se afirmar (ou infirmar) a admissibilidade que possui o aplicador para usar de tais processos integrativos para fins prescritivos.
\end{abstract}

Palavras-chave: Analogia. Interpretação extensiva. Semelhança. Completude. Norma geral inclusiva. Norma geral exclusiva.

\begin{abstract}
:
It is well that the Brazilian order establishes a comprehensive planning and to make such a wholeness and self-sufficiency, using mechanisms such as analogy and extensive interpretation. Either of the two categories studied, we found that, by different methods, they seek to create unity, to cohesion, to close the positive law in order to say that all, absolutely all cases are within the range called solution. Thus, under the charge that the judge deems it all disputes that come to their examination by standard belonging to the system, the legal Brazilian system, prescribes two standards of super level: inclusive general rules, applicable to the type as form-of-construction, and the exclusive, in which the type assumed the tabular form. At first, the very concept of class allows inclusion; in the second, the mandatory condition is self-exclusive, welcoming only those specific requirements that there are broken individualy. On that way, both the analog extension (analogy) and the broad interpretation roots in
\end{abstract}

Doutoranda em Direito Tributário pela Faculdade de Direito do Largo São Francisco, Universidade de São Paulo; endereço eletrônico: florenceharet@hotmail.com. 
higher standards - general inclusive or exclusive - to give power to, by argumentum a simili or contrary, respectively, to build standard that meets the legal case in concrete. Furthermore, the methods of identification of the type - tabulary form or construction"s form are directly related to ways of applying the interpretive law: analog or extensive. This analysis is the answer to say (or invalidate) the admissibility that has applied to use of such integrative processes for prescriptive.

Keywords: Analogy. Broad interpretation. Similarity. Completeness. Generally inclusive rule. Generally exclusive rule.

\section{Introdução}

De início é preciso justificar a relação proposta entre os institutos da analogia e da interpretação extensiva. Em comentário ligeiro, entendemos que nestes dois aspectos, encontramos meios de realização do direito, dando eficácia normativa às regras prescritivas postas. Nos dois, existe elemento de conexão entre um fato e outro que toma por alicerce um fator de semelhança. A similitude é ela mesma fundamento e limitação de tais técnicas interpretativas. As associações entre signos jurígenos feitas a partir deste critério de paridade têm como fonte o próprio direito, sendo o sistema prescritivo o lugar identificador e atributivo de competência para se interpretar analógica ou extensivamente. É, portanto, a partir da ordem positivada que fundamentaremos nossa base cognoscitiva.

Ao fazermos a associação entre analogia e interpretação extensiva ingressamos na contenda da completude do sistema jurídico brasileiro. Questionamos, em um primeiro instante, se o ordenamento posto é realmente completo e, nestes termos, se existem lacunas no sistema e como lidamos com elas.

Das duas categorias ora estudadas, verificamos que, por diferentes métodos, elas buscam criar sentido de unidade, dar coesão, atribuir fechamento ao direito positivo de forma a afirmar que todos, e absolutamente todos os casos encontram solução dentro da ordem posta. Nesta linha, interessante é a afirmação de Savigny: "De fato, o que procuramos estabelecer é sempre a unidade: a unidade negativa com a eliminação das contradições; a unidade positiva com o preenchimento das lacunas" 1

Assim sendo, a presença no direito brasileiro da analogia e da interpretação extensiva, inclusive de forma expressa em artigos de diferentes Diplomas legais, demonstra que a ordem brasileira requer uma completude, isto é, institui um ordenamento completo e, para realizar tal inteireza e auto-suficiência, recorre a mecanismos como os dois acima indicados. A completude no direito brasileiro se apresenta, pois, como dogma, pressuposto, condição necessária para o próprio direito se tornar possível e aplicável em sua inteireza. Tal assertiva pode ser também confirmada pelo pensamento do ilustre jurista

SAVIGNY. F. C. Sistema Del diritto romano attuale. Trad. It. Torino: UTET, 1886. v. 1, seção 42, p. 267. 
italiano Norberto Bobbio que, em seu Teoria do Ordenamento, bem aponta a que tipo de direito a completude é admitida:

Em conclusão, a completude é uma condição necessária para aqueles ordenamentos em que valem estas duas regras: 1) o juiz é obrigado a julgar todas as controvérsias que se apresentam ao seu exame; 2) é obrigado a julgá-las com base em uma norma pertencente ao sistema. ${ }^{2}$

$\mathrm{Na}$ ordem jurídica brasileira, podemos facilmente enunciar aquela primeira regra a que alude o autor, e que, no momento da análise, se faz de extrema importância tê-las ipsis literis. São várias as ocasiões em que o direito brasileiro obriga o juiz a julgar todas as controvérsias, destacaremos aqui aquelas que mais nos interessa para o estudo proposto.

Iniciemos enunciando a Lei de Introdução ao Código Civil (também chamada de "LICC", Decreto-lei n. 4657/42) que prescreve em seu art. $4^{\circ}$ que:

Quando a lei for omissa, o juiz decidirá o caso de acordo com a analogia, os costumes e os princípios gerais de direito.

Nem bem se passaram vinte e quatro anos e o Código Tributário Nacional ("CTN", Lei n. 5172/66) trouxe em seu art. 108 novo dispositivo sobre o assunto:

Na ausência de disposição expressa, a autoridade competente para aplicar a legislação tributária utilizará sucessivamente, na ordem indicada:

I a analogia;

(...)

Por seu turno, o Código de Processo Civil ("CPC" Lei n. 5869/73), em 1973, revigorou a regra enunciando em seu art. 126 o abaixo transcrito:

O juiz não se exime de sentenciar ou despachar alegando lacuna ou obscuridade da lei. No julgamento da lide caberlhe-á aplicar as normas legais; não as havendo, recorrerá à analogia, aos costumes e aos princípios gerais de direito. (Redação dada pela Lei $n^{\circ} 5.925$, de $1^{\circ} .10 .1973$ )

Por tais dispositivos, podemos afirmar, com certa segurança, que o direito positivo brasileiro admite a completude de seu sistema, exigindo que o juiz julgue todas as controvérsias que se apresentam ao seu exame (regra 1 de Norberto Bobbio). Da mesma forma, quanto ao preceito 2 do jurista italiano, o sistema é enfático ao dizer que o juiz é obrigado a julgar com base em uma norma pertencente ao sistema e para tanto basta justificar sua presença tomando emprestados os enunciados que instituem o princípio da

2 BOBBIO, Norberto. Teoria geral do direito. São Paulo: Martins Fontes, 2008. p. 262. 
legalidade na Constituição Federal (art. $5^{\circ}$, II e $150^{\circ}$ I) dentre tantos outros dispositivos infra-constitucionais que poderiam ser elencados e que exigem sempre a lei como veiculo próprio para regular condutas. A propósito, vale a lembrança de que esta é a idéia que fundamenta o princípio ontológico de direito público: "Tudo é proibido, exceto aquilo que é permitido" ou pela negativa "aquilo que não estiver permitido estará proibido"

Com base na premissa da completude sistêmica, portanto, o direito positivo brasileiro vai de certa forma negar a existência de espaços vazios na ordem posta, "preenchendo-os" com normas. Nesta linha, importante fazer breve incursão à teoria das normas gerais exclusiva e/ou inclusiva que, para a temática escolhida, é de suma importância tê-las em vista.

Saquemos a rica doutrina de Ernst Zitelmann ${ }^{3}$ e Donato Donati ${ }^{4}$ em que se inaugurou o pensamento de que, em oposição aos espaços vazios, existiriam no direito espaços cheios nos quais determinadas regras de solução de controvérsias atuariam no sentido de dar significação deôntica ao caso a ser regulado. O preenchimento desses topos seria feito, justamente, pelas normas gerais exclusiva e/ou inclusiva. A primeira, exclusiva, seria aquela regra que prescreve de modo oposto os casos não compreendidos no enunciado deôntico particular. A segunda, inclusiva, é o preceito que determina de modo idêntico os casos não compreendidos na norma particular. No primeiro, o direito utiliza-se de um argumento pela oposição, em contrário (argumentum a contrario); no segundo, de um argumento pela similitude (argumentum a simili). A ressalva quanto a esta teoria fica por conta do critério decisório da aplicabilidade de uma ou outra regra (inclusiva ou exclusiva), isto é, a semelhança entre o fato "não-regulado" e aquel'outro regulado. A aplicação da norma dependerá do resultado do juízo desta indagação, abrindo, por esta fresta, toda a insegurança que porta em si critério com este teor:

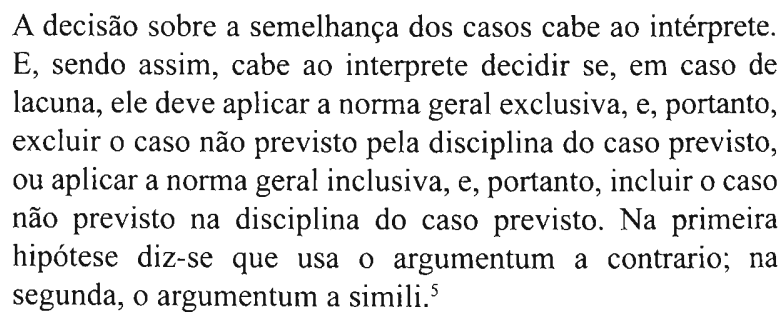

Entendo que, na ordem jurídico-brasileira, as normas gerais exclusivas e as inclusivas existem e convivem entre si. Para tanto, pensemos no subdomínio do Direito Tributário e suas diferentes técnicas de tipificação da conduta. As normas gerais

ZITELMANN ,Ernst. Lücken im Recht. Leipzig : Duncker \& Humblot, 1903.

4 DONATI, Donato. Il problema della lacune nell'ordinamento giuridico. Milano, 1910.

5 BOBBIO, Norberto. Teoria geral do direito. São Paulo: Martins Fontes, 2008. p. 278. 
que instituem tributo conformam o tipo mediante preceito conotativo que, por um lado, pode vir a trazer uma classe, identificando as características gerais e necessárias para a identificação dos indivíduos que a compõem (forma-de-construção); ou, por outro lado, uma enumeração taxativa das pessoas que fazem parte dela (forma tabular). ${ }^{6}$ Entendo que, pela lógica, as normas gerais inclusivas, no Direito Tributário, atuam nos preceitos que instituem tipo pelo método de forma-de-construção; já as normas gerais exclusivas são aplicáveis às regras que constrõem o tipo mediante forma tabular. Na primeira, a própria noção de classe admite, inclusão; na segunda, a taxatividade é condição auto-exclusivista, acolhendo somente aqueles específicos preceitos que lá se encontram discriminados individualmente. A solução parece até hialina se não fosse pelo termo geralmente presente nas listas taxativas "e congêneres", objeto de muitas controvérsias e que mais abaixo falaremos com mais detalhes.

A título ainda introdutório, fiquemos tão só com a presença da idéia de que, no direito brasileiro, inexiste caso não-regulado pelo direito; não há insuficiência de previsão normativa; mas, sim, exuberância de soluções jurídicas. Nesta medida, qual regra deverá ser aplicada pelo intérprete em caso de lacuna ou não regulação expressa da matéria: exclusiva ou inclusiva? Quais os limites da norma geral inclusiva e, por conseqüência, da aplicabilidade dos institutos da analogia e da interpretação extensiva? São essas e outras indagações que buscaremos responder ao longo deste trabalho.

\section{Críticas aos posicionamentos atuais}

Em nome de percorrer o direito como um todo, cumpre não só enunciar a teoria, mas encontrar a sua aplicabilidade na ordem jurídica brasileira. É nesta medida que, antes mesmo de explanar sobre analogia e interpretação extensiva e a relação existente entre elas, será necessário tecer algumas críticas aos posicionamentos atuais da jurisprudência e doutrina quanto a estes institutos.

Em Recurso Especial julgado pelo Desembargador Castro Meira, o Superior Tribunal de Justiça já se pronunciara no intuito de distinguir a analogia da interpretação extensiva:

3. Não se pode confundir analogia com interpretação analógica ou extensiva. A analogia é técnica de integração, vale dizer, recurso de que se vale o operador do direito diante de uma lacuna no ordenamento jurídico. Já a interpretação, seja ela extensiva ou analógica, objetiva desvendar o sentido e o alcance da norma, para então definir-lhe, com certeza, a

6 Sobre o assunto, ver: CARVALHO, Paulo de Barros. Direito tributário, linguagem e método. 2. ed. São Paulo: Noeses, 2009. p. 141. 
sua extensão. A norma existe, sendo o método interpretativo necessário, apenas, para precisar-lhe os contornos. ${ }^{7}$

Tenhamos em vista que tal pensamento é recorrente na disciplina, podendo ser encontrado sob os mesmos formatos na doutrina brasileira, como se depreende dos enunciados abaixo transcritos de Luciano Amaro:

A diferença estaria em que, na analogia, a lei não terá levado em consideração a hipótese, mas, se o tivesse feito, supõese que lhe teria dado idêntica disciplina; já na interpretação extensiva, a lei teria querido abranger a hipótese, mas, em razão de má formulação do texto, deixou a situação fora do alcance expresso da norma, tornando com isso necessário que o aplicador da lei reconstitua o seu alcance. ${ }^{8}$

E continua

(...) a distinção depende de uma incursão pela mente do legislador, pois se baseia, em última análise em perquirir se o legislador 'pensou' ou não na hipótese, para, no primeiro caso, aplicar-se a interpretação extensiva e, no segundo, a interação analógica. ${ }^{9}$

As citações apresentam duas hipóteses que distinguem um instituto do outro: quando a lei se omite e, sendo assim, momento em que atua a analogia e a integração; ou quando a lei for mal escrita, instante em que se interpreta extensivamente. Com todo respeito a ambos pensadores, que em muito contribuem à prática tributária brasileira, peço licença para tecer algumas criticas a ambas fontes acima enunciados, apontando possíveis incorreções epistemológicas.

De pronto, entendo que integrar em nada difere de interpretar. Assim, sendo direito linguagem, não há como atribuir integração a uns e não a outros institutos normativos. Ao se integrar, dá-se a interpretação do enunciado prescritivo, como condição necessária para a construção da regra de direito. Integrar é interpretar. Não vejo como isso pode ser aplicável como elemento distintivo no caso em tela. Outro aspecto, que, da mesma forma, em nada corrobora para fins cognoscitivos, é a dissociação entre as duas causas enunciadas pelo Desembargador, isto é, quando a lei se omite (causa permissiva para a analogia) e quando a lei for mal escrita (causa permissiva para a interpretação extensiva). Primeiro, porque nem sempre é de fácil assunção o preciso lugar em que $a$ lei se omite. Por vários instrumentos interpretativos que o próprio diploma normativo abre espaço como via alternativa - exemplo, analogia e interpretação extensiva ora em

7 STJ, $2^{a}$ T., REsp 121.428/RJ, Rel. Min. Castro Meira, jun/04.

8 AMARO, Luciano. Direito tributário brasileiro. 14. ed. São Paulo: Saraiva, 2008. p. 212.

9 Id. Ibid. 
enfoque - a omissão é só aparente, podendo, dependendo do caso, ser afastada mediante aplicação destas regras de sobrenível. Lembremos, por oportuno, o princípio ontológico de direito público a que alude Norberto Bobbio no início deste tópico: o juiz é obrigado a julgar as controvérsias com base em norma pertencente ao sistema. Logo, ao juiz cabe construir a norma a partir dos mecanismos que o próprio direito o oferece. Da mesma forma, dizer que a lei foi mal escrita é expressão rudimentar que pressupõe juízo pessoal do intérprete. Na maioria das vezes serão os interesses pessoais, inclusive, que irão dizer o que "está mal escrito" Nesta medida, não há como se sustentar tal argumento também.

Por fim, reforcemos o fato de que tão pouco poderíamos assumir como critério distintivo entre analogia e interpretação extensiva a incursão pela mente do legislador como afirma Luciano Amaro, tendo em vista que este encontra-se no domínio do inefável: o que o legislador pensou é irrecuperável no tempo e no espaço, não servindo, pois, como elemento apropriado para diferençar as categorias em análise. Logo, supor que o legislador teria dado idêntica disciplina de um fato regulado a outro não regulado (ao menos expressamente) na analogia ou afirmar ser esta ou aquela a vontade da lei ("a lei teria querido abranger a hipótese") na interpretação extensiva é instaurar a discricionariedade ao aplicador e sua consequente insegurança jurídica, razão pela qual discordarei destes posicionamentos adotados.

Para além do rigor, vê-se que a dissociação feita entre analogia e interpretação extensiva parte de dois pressupostos diferentes: analogia em vista de espaços vazios no direito positivo (lacuna); interpretação extensiva em face de espaços cheios no ordenamento ("desvendar o sentido e alcance da norma"). Sendo assim, importante repisar a necessidade, ao se comparar um instituto a outro, de se partir de premissas idênticas afim de que, com base nelas, possa alcançar conclusões coerentes.

Tenho para mim que toda solução jurídica está no direito, ou seja, encontra suas regras dentro da linguagem prescritiva de conduta: nas normas postas. Assim sendo, tanto a extensão analógica (analogia) quanto a interpretação extensiva buscam seus fundamentos em normas superiores - normas gerais inclusivas e/ou exclusivas - que lhe dão competência para, mediante argumentum a simili ou a contrario, construir a norma que dá resposta jurídica ao caso em concreto.

Norberto Bobbio procede a distinção entre estes institutos apontando os diferentes efeitos que cada qual produz:

(...) compreender a diferença em relação aos diversos efeitos, respectivamente, da extensão analógica e da interpretação extensiva: o efeito da primeira é a criação de uma nova 
norma jurídica; o efeito da segunda é a extensão de uma norma a casos não previstos por ela.

Para ele, portanto, extensão analógica cria nova norma jurídica; interpretação extensiva, amplia a norma a casos não previstos por ela. E com base nesta distinção, afirma não ser admitido, no direito penal, a extensão analógica. ${ }^{11}$

Sabemos que os subdomínios do direito penal e tributário são semelhantes na medida em que trabalham essencialmente com a noção de tipo. Tende para uma maior rigidez, requerendo uma série de formalidades, prescritas em lei, para a construção do tipo no caso concreto (subsunção do fato à hipótese). É nesta linha que quero reforçar estar os modos de identificação do tipo - forma-de-construção ou tabular - diretamente relacionados às maneiras interpretativas de aplicação do direito: analógicas ou extensivas. Está nesta análise a resposta para se afirmar (ou infirmar) a admissibilidade que possui o aplicador para usar de tais processos integrativos para fins prescritivos.

Assim sendo, não acredito que haja, como afirma o jurista italiano, o efeito de criação de nova norma jurídica na analogia, mas, sim, processo interpretativo de inclusão de classe. Autorizado por norma geral inclusiva, o aplicador do direito tem competência para proceder extensão analógica de regra que prevê solução jurídica de um caso a outro que lhe é similar incluindo este à classe dos objetos daquele. A analogia é procedimento intelectivo próprio dos tipos com base em forma-de-construção. Lembrando sempre que partimos do pressuposto de uma suposta completude do sistema - espaços cheios - razão pela qual é possível dizer ser o próprio direito posto que autoriza este processo interpretativo.

Por outro lado, ao referirmos à interpretação extensiva, entendo, conforme citação supra, ocorrer, sim, a extensão de uma norma, porém não a casos não previstos por ela pois, se assim o fosse, simplesmente o aplicador seria incompetente para proceder desta forma. A premissa aqui também são os espaços cheios no direito. A extensão pode dar-se de duas maneiras, de acordo com o modo de tipificação. Sendo forma-de-construção, analogia e interpretação extensiva se emparelham, significando o mesmo processo interpretativo: inclusão de classe. Contudo, a diferença se apresenta efetivamente, na forma tabular, em que, aí sim, a interpretação extensiva impera como meio de estender-se o conceito do tipo àquele caso em concreto: dentre as diversas pessoas, coisas, lugares, entre outros, enumerados que fazem parte do conjunto, toma-se um e estende-se o conceito deste àquele que se quer abarcar, como se ele lá estivesse desde o princípio, desde o momento em que se procedeu a enunciação da norma.

BOBBIO, Norberto. Teoria geral do direito. São Paulo: Martins Fontes, 2008. p. 294.

Id. Ibid., p. 279. 
Não sobeja lembrar que uma coisa é o raciocínio acima explicado, outra é o que ocorre, também na forma tabular, com a expressão "e congênere" Na primeira hipótese, o direito parte de norma geral exclusiva; na segunda, que iremos depurar melhor agora, toma como ponto de partida norma geral inclusiva, voltando-se, portanto, para a teoria das classes e dos conjuntos e, nesta medida, ao raciocínio aplicado às formas-deconstrução do tipo e não mais ao método tabular.

Ao mencionar "e congênere" a taxatividade, da maneira como ela deve ser lida, cai por terra. Deixa de ser tabular, para tornar-se forma-de-construção. Diz-se congênere aquilo "que é do mesmo gênero, espécie, tipo, classe, modelo, função etc"12, também aquilo "que tem natureza, finalidade ou caráter semelhante (aos de outro)" 13 ou, por fim, "que tem a mesma origem" ${ }^{14}$ Em outras palavras, o congenérico é algo que está na mesma classe daquilo que lhe é comparado, isto é, nela está incluído. Logo, retornamos ao procedimento de inclusão de classe próprio das formas-de-construção. Dito de outro modo, a forma tabular ou taxativa admite interpretação extensiva, desde que, e na medida em que, a lei não abra fissura com expressões de teor inclusivo, aplicando-se-lhe, pois, a regra geral inclusiva.

Feitas as ilações primordiais quanto aos institutos em enfoque, cumpre agora tecer comentários isolados de cada qual para se atender o objetivo buscado neste trabalho: a aplicabilidade da analogia ou interpretação extensiva no domínio dos tributos.

3. Algumas palavras sobre analogia

Firmemos que analogia é meio de interpretação do direito, que trabalha com base em argumentum a simili. Em verdade, é ela mesma instrumento ou ferramenta básica para que se possa presumir, equiparar, etc. Ferdinand Saussure já destacara que, na sua base, a analogia "considerada em si mesma, não passa de um aspecto do fenômeno de interpretação, uma manifestação da atividade geral que distingue as unidades para utilizá-las em seguida. Eis porque dizemos que é inteiramente gramatical e sincrônica" 15 Saquemos também a rica definição de Norberto Bobbio ao delinear o sentido que emprega ao termo:

Entende-se por 'analogia' aquele procedimento pelo qual se atribui a um caso não-regulado a mesma disciplina de um caso regulado de maneira semelhante. (...) A analogia é certamente o mais típico e o mais importante dos

\footnotetext{
HOUAISS, Antônio e VILLAR, Mauro de Salles. Dicionário Houaiss da Lingua Portuguesa. Rio de Janeiro: Objetiva, 2001, p. 800.

13 Id. Ibid.

14 Id. Ibid.

15 SAUSSURE, Ferdinand: Curso de lingüistica geral. São Paulo. Ed. Cultrix, p. 193
} 
procedimentos interpretativos de um determinado sistema normativo: é aquele procedimento mediante o qual se manifesta a chamada tendência de todo sistema jurídico a expandir-se para além dos casos expressamente regulados. ${ }^{16}$

Levemos em conta essas injunções para afirmar que, através da assunção de critério de semelhança relevante, a analogia aparece no direito como técnica prescrita em lei que tem por fim fazer o intérprete deduzir a norma aplicável a determinado caso. A similitude relevante deverá ser razão suficiente "de uma lei" qu que permite a extensão analógica de um caso a outro, atribuindo a fato dito "não-regulado" a mesma disciplina de fato regulado de maneira semelhante. Assim é que o direito dispõe ser necessário que os dois casos, aquele regulado e o "não-regulado" tenham em comum a ratio legis. ${ }^{18}$ Em outras palavras, entre um fato e outro há de ter-se um genus comum. É neste que iremos encontrar o nexo de relação de uma coisa com a outra. Estabelecido o vínculo, a conseqüência é a admissão jurídica de que ambos possam ocupar a mesma posição ontológico-formal em termos regulatórios de conduta.

Firmemos que existem diferentes níveis relacionais que o direito pode atribuir a duas coisas, a dois objetos, a dois fatos: um, mais estreito, toma por base comparativa elemento essencial; outro, menos intenso, assume por critério características secundárias. Aquele releva "aquilo que é o mais básico, o mais central, a mais importante característica de um ser ou de algo, que lhe confere uma identidade, um caráter distintivo" 19; este, secundário, por exclusão, tudo que não pertença ao primário ou essencial. Na analogia, "acrescentou-se a uma norma específica uma outra norma específica, remontando a um genus comum", ${ }^{20}$ Tal elemento conectivo de similitude deve-ser, em termos de interpretação analógica, essencial, próprio da razão do ser - juridicamente considerado do objeto, isto é, próprio da existência no direito da coisa. Di-lo da mesma forma Tercio Sampaio:

16 "no direito penal, em que a extensão analógica não é admitida, poderíamos também dizer que não existem lacunas: todos os comportamentos que não são expressamente proibidos pelas leis penais são lícitos. (BOBBIO, Norberto. Teoria geral do direito. São Paulo: Martins Fontes, 2008. p. 291).

17 Ponho em aspas "de uma lei" pela distinção que se utiliza corriqueiramente entre analogia legis e analogia iuris. Na primeira (legis), interpretando analogicamente um fato por meio da utilização de certa norma posta no sistema; na segunda (iuris), justificando o emprego da analogia por meio dos principios integrantes do ordenamento positivo, e não de uma norma específica. Em outras palavras, por meio da interpretação sistemática, cria-se nova norma para disciplinar extensivamente fato, que antes não existia para o universo jurídico.

18 BOBBIO, Norberto. Teoria geral do direito. cit., p. 293.

19 Assim, define-se Essência in HOUAISS, Antônio e VILLAR, Mauro de Salles. Dicionário Houaiss da Lingua Portuguesa. Rio de Janeiro: Objetiva, 2001, p. 1242.

20 BOBBIO, Norberto. Teoria geral do direito. cit., p. 295. 
(...) a analogia pressupõe a igualdade essencial (e a desigualdade secundária) em relação a uma categoria. ${ }^{21}$

Deste modo, como ferramenta de interpretação do direito, a analogia é o processo de positivação de uma norma que, para fins de subsunção de um fato, sem norma precisa que lhe dê tratamento, toma por pressuposto semelhança essencial entre dois suportes fáticos. O genus comum, e essencial, deste modo, justifica a própria assunção de uma ratio legis única para ambos os casos, razão suficiente para se proceder, e conferir competência ao aplicador do direito para, interpretação analógica. Em outras palavras, em toda analogia, o importante é que se visualize uma semelhança essencial, e necessária, entre um fato e outro, independentemente de que ocorram diferenças secundárias, que em nada impediram a sua aplicabilidade.

A aludida semelhança deve trazer similitude essencial para o direito, ou seja, nexo associativo com relevância jurídica e não mero critério ao sabor dos interesses do intérprete. A ratio legis, como o próprio nome o indica, é a razão que se encontra no texto legal, a causa que a lei estabelece como sobresaliente em termos jurídicos, devendo-se buscar tanto os motivos quantos os efeitos deste genus comum nos enunciados do direito positivo sempre, e nunca fora dele. Assim também é o entendimento de Tercio Sampaio Ferraz Junior:

$\mathrm{O}$ uso da analogia no direito funda-se no princípio geral de que, para os mesmos casos, deve haver a mesma razão dispositiva. Segue daí que possíveis semelhanças devem ser apontadas tendo em vista razões e efeitos jurídicos e não meras semelhanças ditadas por critérios quaisquer. (...) Isso limita o procedimento analógico por elas requerido. Para haver equiparação é preciso, pois, demonstrar uma semelhança essencial não com a figura de um importador ou de um industrial em geral, mas como sujeitos de um determinado imposto. ${ }^{22}$

Feitas as colocações a respeito da analogia, cumpre agora trazer à baila algumas idéias quanto a interpretação extensiva.

4. Algumas palavras sobre interpretação extensiva

Supomos demonstrado que a interpretação extensiva é admitida corriqueiramente em duas acepções: como sinônimo de analogia, trabalhando, portanto,

21 FERRAZ JR., Tércio Sampaio. Equiparação - CTN, art. 51. Cadernos de Direito Tributário e Finanças Públicas, São Paulo, ano 7, n. 28, p. 109-14, jul./set. 1999.

22 FERRAZ JR., Tércio Sampaio. Equiparação - CTN, art. 51. Cadernos de Direito Tributário e Finanças Públicas, São Paulo, ano 7, n. 28, p. 109-14, jul./set. 1999. 
com argumento a simili; e como interpretação extensiva propriamente dita, desenvolvendose com base em argumento a contrario. No primeiro caso, o que se aplica à analogia é aproveitado à interpretação extensiva, uma vez que diz respeito ao mesmo fenômeno interpretativo que alcança determinado objeto em vista de nexo de semelhança. Assim, por exemplo, dá-se nas listas taxativas especificamente nos itens que trazem a expressão "e congêneres" ou outros termos com este sentido e que, por conta desta abertura da lei, modifica o caráter tabular do inventário para uma forma-de-construção. Outro é o momento, no segundo caso, da interpretação extensiva propriamente dita em que aí, sim, com base em argumento em contrario veda-se a inclusão de classe.

Retornemos da digressão para considerar algumas peculiaridades próprias da interpretação extensiva em sentido estrito acima mencionada. Diferentemente da extensão analógica, na interpretação extensiva, o alargamento dá-se com base no próprio termo, a partir de redefinição daquilo indicado em lei. A modificação (extensiva) acontece nos próprios critérios que definem a coisa. Logo, é ela mais restritiva em face da analogia, pois o gênero, aqui, não é uma classe mas o objeto em si, ou melhor, a descrição ou demarcação da coisa. Aquilo que se quer abraçar no conceito regulado, deve estar dentro dele - conceito - sendo necessário, portanto, que todos os critérios essenciais que definam um sejam definíveis ao outro. A semelhança deve se dar na ordem essencial, principalmente, mas também em nível secundário pois o objeto que se quer ver regulado deve estar dentro e no conceito daquel'outro indicado em lei. Ou seja, os fatores comparativos entre um elemento e outro não são os da classe em que ele se insere mas os do próprio objeto, individualmente considerado. Fora dessas ocasiões, encontrando-se diferenças da ordem essencial e/ou secundária, deve-se excluí-los do conceito regulado com base em argumento a contrario. Logo, a diferença - essencial e/ou secundária - é fator, e justificativa, de exclusão de um objeto ao conceito do outro, não podendo-se juridicizar aquele com base neste.

Tenhamos em mente que, na interpretação extensiva, existe uma norma precisa que dá tratamento ao objeto regulado, e, com base na extensão do conceito deste ao outro, é que se dá a interpretação extensiva. Desta forma, é que se pode afirmar que a interpretação extensiva não criou uma regra nova, mas simplesmente ampliou-se o alcance da norma posta. Assim é que, com ela, "nos limitamos à redefinição de um termo, mas a norma aplicada é sempre a mesma" 23

Pondere-se, por fim, tão somente que, na tarefa de redefinição acima referida da interpretação extensiva, a lei tributária não pode alterar o conteúdo e o alcance de institutos, conceitos e formas de direito privado, utilizados, expressa ou implicitamente, pela Constituição Federal, pelas Constituições dos Estados, ou pelas Leis Orgânicas do Distrito Federal ou dos Municípios, para definir ou limitar competências tributárias, tal

23 BOBBIO, Norberto. Teoria geral do direito. São Paulo: Martins Fontes, 2008. p. 295 
como dispõe o art. 110 do CTN. O que não significa que na interpretação extensiva não se possa atualizar a significação contida no termo. Lembremos neste ponto que: “(...) o que caracteriza o Direito Positivo, no mundo contemporâneo, é a sua contínua mudança"24 que se faz presente na complexidade das relações humanas, mas também na linguagem, e nos termos nela definidos, que descreve tais eventos sociais. A interpretação extensiva, nesta medida, não deve trazer nada de novo, mas sim o novo se apresenta na própria atualização do conceito.

5. Aplicabilidade da analogia ou interpretação extensiva nos tributos

Com bases nestes torneios, pudemos relevar outrossim que analogia e interpretação extensiva são conceitos aproximados, e, dependendo do caso, até sinônimos. Porém, em dado momento, adquirem sentidos que se opõem pelo vértice. Na parte em que são iguais, isto é, quando ambos trabalharem com argumento a simili, o que se aplica a uma, dá-se com a outra, não sendo, por isso, necessário relacionar novamente o que foi dito àquela. O que vai nos interessar será a parte em que a interpretação extensiva não coincide com a analogia e é a partir desta dissociação que iremos demonstrar a aplicabilidade da analogia ou interpretação extensiva no ramo dos tributos.

Como regra geral, o CTN dispõe que, na ausência de disposição expressa, a autoridade competente para aplicar a lei tributária utilizará a analogia (art. 108, I). Como já demonstrado acima, a norma é claramente inclusiva, admitindo ao aplicador a utilização de construções interpretativas com base na semelhança entre os termos comparados. Nestes casos, o emprego da analogia nos leva ao reconhecimento de interpretação ampliativa. Sabemos contudo que, no domínio tributário, determinadas matérias voltadas à instituição, fiscalização e arrecadação de tributos adquirem maior peso e, por conseqüência, rigidez em sua disciplina. Em várias ocasiões o Código enumera tais casos, vedando, pois, o uso da analogia nestas específicas situações. Assim se apresenta, por exemplo, as hipóteses de:

(i) instituição ou aumento de tributo (Art. $108, \S 1^{\circ}$ )

(ii) reconhecimento de isenção (Art. 111, I e II)

(iii) concessão de anistia (Art. 111, I)

(iv) dispensa de obrigações acessórias (Art. 111, III)

24 LAFER, Celso. A ruptura totalitária e a reconstrução dos direitos humanos: um diálogo com Hannah Arendt. São Paulo. Tese de concurso para provimento de cargo de professor titular do Departamento de Filosofia e Teoria Geral do Direito da Faculdade de Direito da USP, 1988. p. 53. 
Reforcemos a idéia de que a vedação à analogia ou extensão analógica deve ser expressa na lei, tal como ocorre nos dispositivos acima indicados. Agora, com supedâneo em tais vedações, tenho que o preceito nos impõe, por oposição, a aplicabilidade da interpretação extensiva. Em abono deste matiz, importante anotar que sendo desautorizado o uso de analogia por lei, deve-se aplicar a interpretação extensiva: a proibição do argumento a simili nos remete ao uso do argumento em contrário. Posto isto, onde é vedado o uso de analogia, vê-se que não estamos mais no campo do tipo forma-de-construção, mas no domínio do modo prescritivo tabular, onde se concentra a aplicabilidade da interpretação extensiva e, por conseqüência, da regra geral exclusiva. Assim, "considera-se em geral que quando a extensão analógica é proibida, como, por exemplo, (...) nas leis penais e nas leis excepcionais, a interpretação extensiva é lícita" ${ }^{25}$ Eis nossa primeira grande conclusão nesta difícil temática.

Transportando esse pensamento ao subdomínio do Direito Tributário, verificamos que determinados princípios informadores deste subsistema tangenciam a matéria ora em análise, apontando limitações tanto para o Poder legislativo, na expedição das leis sobre o assunto, quanto para os Poderes executivos e judiciários, na aplicação das mesmas. Nesta linha, é que se coloca o princípio da tipicidade tributária, como expressão da legalidade, que impõe diferentes coordenadas ao legislador e ao aplicador.

Ao legislador, o direito estabelece imposição de descrever na lei todos os critérios que compõem o enunciado deôntico completo da regra matriz de incidência. Em outras palavras, é obrigação de quem põe a lei tributária definir, em regra, de modo taxativo (numerus clausus) as condutas reguladas, tanto no fato-antecedente, enunciado que deve ser suficiente para desencadear o prescritor, quanto no fato-conseqüente da norma tributária, relação jurídica necessária uma vez ocorrido (relatado em linguagem competente) o descritor.

Ao aplicador, por sua vez, pela via da tipicidade informadora do ordenamento tributário, o sistema prescreve o comando de dever-se encontrar e constituir em linguagem competente - provas em direito admitidas - todos os critérios que necessariamente compõem o enunciado deôntico completo da regra matriz de incidência para fins de regular a conduta. Neste sentido, nas matérias em que o ordenamento tributário expressamente requer forma tabular de regulação, veda-se a analogia, incompatível com a taxatividade e determinação dos tipos tributários, mas admite-se, como já afirmado acima a interpretação extensiva. Exemplificando bem o que acabamos de defender está julgado abaixo do Conselho de Contribuintes:

IRPJ - A tipicidade cerrada do fato gerador e a estrita legalidade são impeditivas a interpretações da legislação

25 BOBBIO, Norberto. Teoria geral do direito. São Paulo: Martins Fontes, 2008. p. 294. 
para a efetivação ou sustentação de lançamento tributário em condições ou circunstancias legais e expressamente não autorizadas, sendo, neste contexto, incabível o emprego de analogia (CTN, artigo $\left.108, \S 1^{\circ}\right)$. Recurso provido. ${ }^{26}$

No Direito Tributário, portanto, instituição e/ou aumento de tributo, como no caso acima, não admite extensão analógica. O que, no máximo podemos defender, é sim ser possível aplicar interpretação extensiva nestas matérias em que a tipicidade é o principio informador, mas não no sentido de que a extensão admite o criar novo sentido ao termo, mas o "novo" é a própria atualização do termo ou, na melhor das hipóteses, a paridade de um conceito a outro em vista de semelhança de elementos essenciais entre eles. É o que se dá, por exemplo, em alguns casos da lista de serviços anexa à Lei Complementar n. 116, de 31 de julho de 2003.

ISSQN...LISTA DE SERVIÇOS. INTERPRETAÇÃO EXTENSIVA...A interpretação extensiva, para fazer incidir ISSQN sobre atividades semelhantes àquelas previstas na lista de serviços, constitui mecanismo distinto da analogia (vedada no art. 108, I, do CTN) e não acarreta irregularidades ou invalidade. $[\ldots]^{27}$

Dou por assente que, nos inventários taxativos da legislação tributária (forma tabular), como é o caso da lista anexa acima indicada, a extensão é perfeitamente aplicável, fazendo-se presente aqui o método interpretativo restritivo dos termos. Lembremos bem que a reserva dá-se em face da própria condição do procedimento extensivo. Nesse ponto, é preciso dizer enfaticamente que o fundamento da interpretação extensiva pede que entre as duas coisas - a juridicamente regulada e a estendida à esta - haja a mesma essência. $\mathrm{Na}$ falta desses dados essenciais semelhantes entre eles, não se pode aplicar a interpretação extensiva, caindo na regra do argumento em contrário. Ou se está no conceito, e, por conta disso, segue a regra prescrita em lei; ou não se está e, deste modo, não se lhe aplica, uma vez ausente a norma jurídica, sendo tal realidade irrelevante para o universo jurídico.

\section{Enfim...}

É mediante essa exuberância de regras de sobrenível para fins de solucionar o caso em concreto que o direito assume a analogia, nas formas-de-construção do tipo tributário, e a interpretação extensiva, no modo tabular. A extensão analógica, tomando por base semelhança essencial, e necessária, independentemente das diferenças secundárias,

26 Conselho de Contribuintes, Processo 10980.007402/96-17, $4^{\circ}$ Câmara, Relator: Roberto William Gonçalves, Data da Sessão: 09/12/1997.

27 TJRS, $22^{\mathrm{a}}$ Câm. Cível, Rel. Desa. Mara Larsen Chechi, out/04. 
entre a classe da hipótese e o fato, deduz a ratio legis, subsumindo aquele suporte fáctico sem norma precisa que lhe dê tratamento à classe hipotética regulada em lei que lhe é similar. Diferentemente na interpretação extensiva, a semelhança se dá não em termos de classe mas do objeto em si, na própria definição da coisa. Mais restritiva como técnica de interpretação, o que se pretende é abraçar no conceito regulado a noção daquilo que se quer juridicizar. A semelhança, neste domínio, deve acontecer tanto em planos essenciais, como em termos secundários, de modo que aquilo que se quer regular deve estar dentro e no conceito daquel'outro indicado em lei. Ora, encerrando o tema, de ver está que a assimilação tanto na analogia quanto na interpretação extensiva insere exceções, devendo, pois, e principalmente no campo dos tributos, ser tratadas com prudência e vigilância, sob pena de provocarem disfunções ou efeitos indesejáveis na aplicação do sistema normativo. Eis que a interpretação, em ambos os casos, deve preponderar, em regra, na forma restritiva.

São Paulo, junho de 2009.

\section{Referências}

AMARO, Luciano. Direito tributário brasileiro. 14. ed. São Paulo: Saraiva, 2008

BOBBIO, Norberto. Teoria geral do direito. São Paulo: Martins Fontes, 2008.

CARVALHO, Paulo de Barros. Direito tributário, linguagem e método. 2. ed. São Paulo: Noeses, 2009.

DONATI, Donato. Il problema delle lacune nell'ordinamento giuridico. Milano, 1910

FERRAZ JR., Tércio Sampaio. Equiparação - CTN, Art. 51. Cadernos de Direito Tributário e Finanças Públicas, São Paulo, ano 7, n. 28, jul./set. 1999.

HOUAISS, Antônio; VILLAR, Mauro de Salles. Dicionário Houaiss da Lingua Portuguesa. Rio de Janeiro: Objetiva, 2001.

LAFER, Celso. A ruptura totalitária e a reconstrução dos direitos humanos: um diálogo com Hannah Arandt. São Paulo: Tese de concurso para provimento de cargo de professor titular do Departamento de Filosofia e Teoria Geral do Direito da Faculdade de Direito da USP, 1988.

SAUSSURE, Ferdinand: Curso de lingüistica geral. São Paulo. Ed. Cultrix.

SAVIGNY. F.C. Sistema Del diritto romano attuale. Trad. It. Torino: UTET, 1886. v. 1, seção 42. ZITELMANN, Ernst. Lücken im Recht. Leipzig: Duncker \& Humblot, 1903. 